\title{
Child-Pugh Clinical Classification
}

National Cancer Institute

\section{Source}

National Cancer Institute. Child-Pugh Clinical Classification. NCI Thesaurus. Code

C121007.

A standardized rating scale used to assess the severity of liver cirrhosis and determine the prognosis, the required strength of treatment, and the necessity of liver transplantation. This instrument uses the following clinical and lab criteria: encephalopathy grade, ascites, bilirubin, albumin, and prothrombin index. 